\title{
International Requirements for Large Integration of Renewable Energy Sources
}

Molina-Garcia, A.; Hansen, Anca Daniela; Muljadi, Ed; Gevorgian, Vahan; Fortmann, Jens; GomezLazaro, E.

Published in:

Large Scale Grid Integration of Renewable Energy Sources

Link to article, DOI:

10.1049/PBPO098E_ch2

Publication date:

2017

Document Version

Peer reviewed version

Link back to DTU Orbit

Citation (APA):

Molina-Garcia, A., Hansen, A. D., Muljadi, E., Gevorgian, V., Fortmann, J., \& Gomez-Lazaro, E. (2017). International Requirements for Large Integration of Renewable Energy Sources. In A. Moreno-Munoz (Ed.), Large Scale Grid Integration of Renewable Energy Sources (pp. 29-57). Institution of Engineering and Technology. https://doi.org/10.1049/PBPO098E_ch2

\section{General rights}

Copyright and moral rights for the publications made accessible in the public portal are retained by the authors and/or other copyright owners and it is a condition of accessing publications that users recognise and abide by the legal requirements associated with these rights.

- Users may download and print one copy of any publication from the public portal for the purpose of private study or research.

- You may not further distribute the material or use it for any profit-making activity or commercial gain

- You may freely distribute the URL identifying the publication in the public portal 


\title{
International Requirements for Large \\ Integration of Renewable Energy Sources
}

\author{
A. Molina-García, A.D. Hansen, E. Muljadi, V. Gevorgian, \\ J. Fortmann, E. Gómez-Lázaro
}

\section{General Overview}

Most European countries have concerns about the integration of large amounts of renewable energy sources (RES) into electric power systems, and this is currently a topic of growing interest. In January 2008, the European Commission published the 2020 package, which proposes committing the European Union to a $20 \%$ reduction in greenhouse gas emissions, to achieve a target of deriving $20 \%$ of the European Union's final energy consumption from renewable sources, and to achieve $20 \%$ improvement in energy efficiency both by the year 2020 [1]. Member states have different individual goals to meet these overall objectives, and they each need to provide a detailed roadmap describing how they will meet these legally binding targets [2]. At this time, RES are an indispensable part of the global energy mix, which has been partially motivated by the continuous increases in hydropower as well as the rapid expansion of wind and solar photovoltaic (PV). The International Energy Agency's 2012 edition of the World Energy Outlook stated that the rapid increases in RES integration are underpinned by falling technology costs as well as rising fossil-fuel prices and carbon pricing, but RES integration is also encouraged by continued subsidies: from $\$ 88$ billion globally in 2011 (compared to $\$ 523$ billion in fossil-fuel subsidies in 2012 [3], with a share of $\$ 131$ billion for electricity generation) to an estimated $\$ 240$ billion in 2035 [4]. According to [3], in 2015 RES accounted for 22\% of electricity generation, which was approximately the same level as gas and about one-half the level of coal. Projecting into the future, it is estimated that by 2035 RES will account for almost one-third of total electricity generation, becoming the world's largest source of electrical power generation [3]. Nevertheless, to avoid excessive burdens on governments and consumers, subsidy measures to support new renewable energy projects need to be adjusted over time as power capacity increases and as the costs of renewable technologies fall [4]. Therefore, during the last decade, concerns about global 
climate change, finite conventional resources, and decreasing costs of renewables have been major arguments to justify the inclusion of RES and energy-efficiency policies in a significant number of countries [5]. In fact, most developed countries have been promoting policy principles and incentives to turn efficient and renewable scenarios into reality, and several are pushing for major renewable energy integration [6], [7]. In this context, and aiming to reduce dependence on fossil fuels and foreign energy sources, electricity emerges as a sector wherein renewable energy policies and energy-efficient initiatives are most likely to be implemented because it can be generated from a large variety of fuels and technologies.

Moreover, $75 \%$ of the energy consumed by the residential/commercial sector is in the form of electricity, and approximately $35 \%$ of industrial energy consumption is in the form of electricity [10]. Current climate policy agreements in Europe require a reduction of at least $80 \%$ of all carbon-dioxide $\left(\mathrm{CO}_{2}\right)$ emissions by 2050 , eventually leading to the full decarbonization of the power sector [11]. Consequently, in European countries the ratio of conventional power plants has been gradually decreasing while RES are becoming more relevant [12]. In this respect, nuclear energy could be considered an alternative and potential solution as a carbon-free energy source; however, as discussed in [14], nuclear technologies currently present some relevant drawbacks. For example, the Fukushima Daiichi incident has raised the public's concerns about nuclear energy, emphasizing the fundamental safety weaknesses and potential inspiration for terrorism activities. Thus, despite significant growth in low-carbon sources of energy-shifts away from oil and coal toward natural gas and renewable sources - fossil fuels remain dominant in the global energy mix [15]. Displacing fossil fuel-based generation with renewable generation presents many desirable outcomes within the power sector, such as the reduction in pollution and $\mathrm{CO}_{2}$ emissions. Also, resolving significant challenges can be met through these actions-for example, the reliable delivery of electrical power of acceptable quality nearly $100 \%$ of the time [16].

In the electrical sector, global installed capacity of RES was approximately 3.6 GW in 2000, representing $22.4 \%$ of new power capacity installations [17]. This capacity increased up to 47.4 GW in 2013 , accounting for more than $72 \%$ of new installations. In 2014 , the share of renewables in total electricity production exceeded 22\%; hydropower accounted for $16.4 \%$, and variable renewable energy (VRE) (e.g., PV and wind) for 3.6\%. A number of countries already have a significantly higher individual share of VRE than the global figure. Denmark, Spain, Ireland, and Germany, for example, each have a share of more than $15 \%$. Actually, the increased penetration 
of renewable energy to attain the goal of the Danish government to convert the present energy system into an entire renewable energy integrated system by the end of 2050 [17], will be accomplished by large scale of WP and PV plants. For example, the WP generation capacity in Denmark of $4792 \mathrm{MW}$, supplying 33.2\% of total electricity consumption in 2013 [18], being increased to $6700 \mathrm{MW}$ already in 2020 [19]. According to [20], the PV generation capacity in Denmark of 610 MW in 2014 will be increased at 1000 MW in 2020 [21]. The International Renewable Energy Agency (IRENA) analysis indicates that the global share of VRE can be expected to increase by as much as $20 \%$ by 2030 [22]. Wind and PV resources are among the top technologies, with more than $115.4 \mathrm{GW}$ and $80 \mathrm{GW}$ installed, respectively [23]. According to [24], no other technology has reached or will reach enough maturity to challenge PV, wind, or natural gas in the next five years. In fact, wind power had a record-breaking year in 2014 after passing $50 \mathrm{GW}$ for the first time, and it reached another milestone in 2015 as annual installations topped $63 \mathrm{GW}$, a $22 \%$ increase. China led the way, with a record $30.8 \mathrm{GW}$ of new installed capacity, breaking the previous record it had set (in 2014) for installations in a single year [25]. Nevertheless, other renewable technologies (hydropower, biomass, concentrating solar power (CSP), geothermal, and ocean energies) have also increased in installed capacity during the past decade but to a lesser degree [26]. Figure 1 shows the global net additions to renewable power capacity, both historical and as forecasted. During the past three years, PV power plants have been the largest generation source in terms of installed capacity in Europe. Indeed, in 2013 the installation of PV power plants was more than $11 \mathrm{GW}$ (31\% of total capacity). This was only slightly behind wind power plants, with approximately $11.2 \mathrm{GW}$ (31\%); and natural gas, with 10.5 GW (23\%). The installations of the remaining resources, including renewables as conventional types of generation, are far from these values. Figure 2 shows the estimated share of RES in global final energy consumption. 


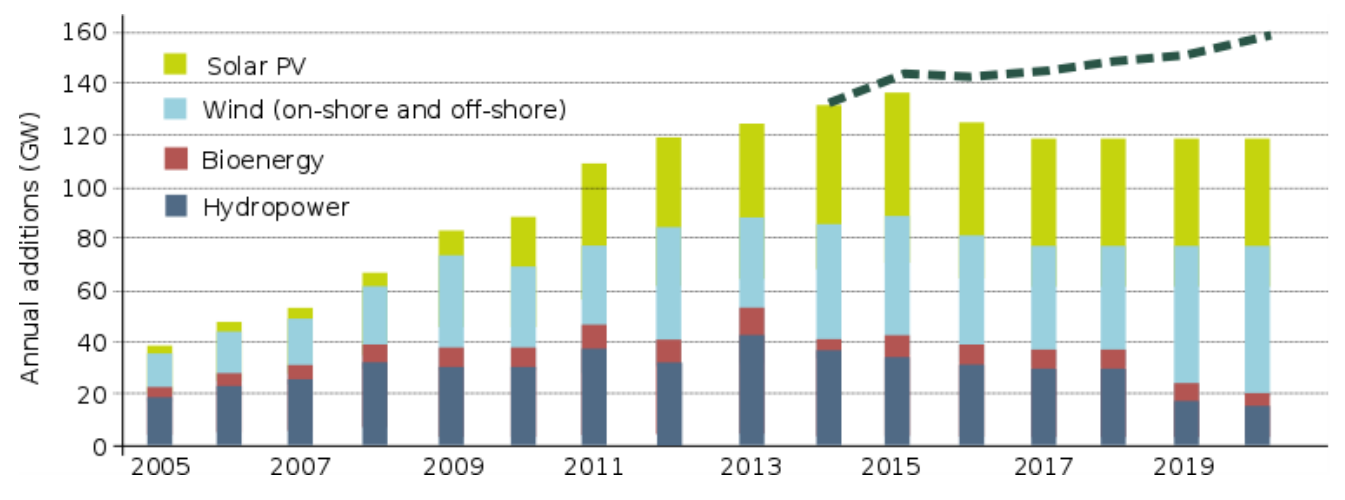

Figure 1: Global net additions to renewable power capacity-historical and forecast [8]

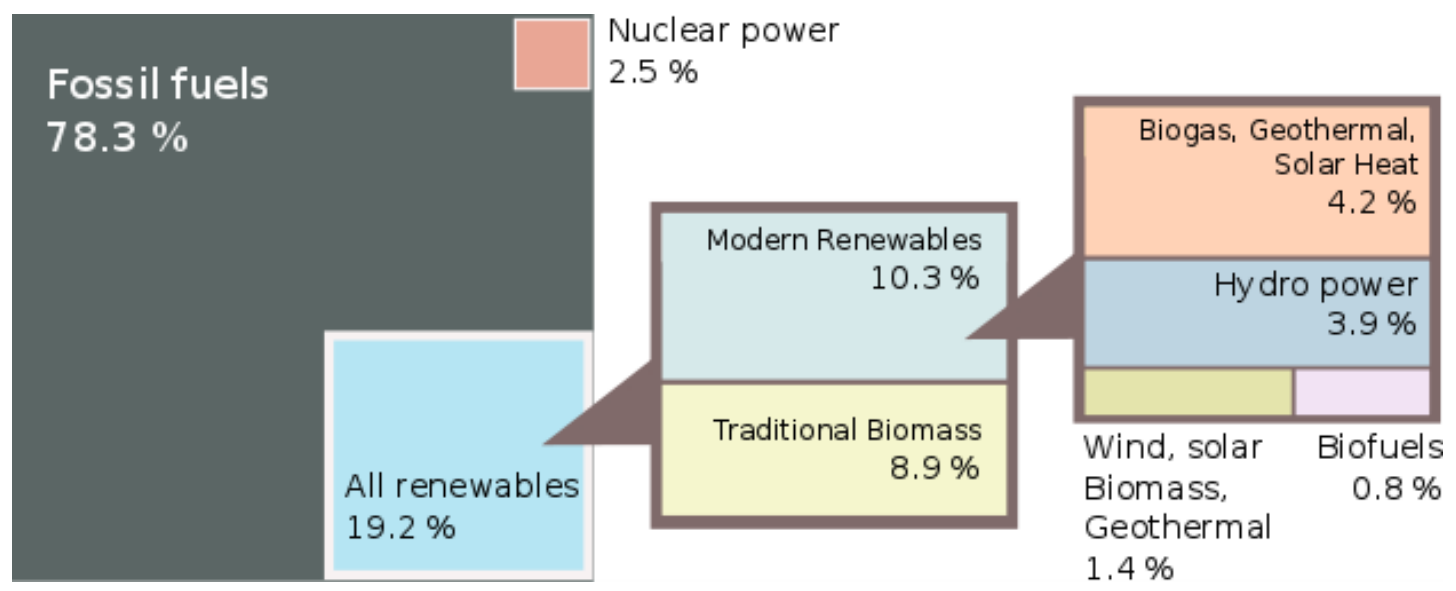

Figure 2: Estimated share of RES in global energy consumption [9]

\section{Ancillary Services in RES: Comparisons Among Different Countries}

The forecasted integrations of high penetrations of RES, such as wind and PV, into the electricity supply around the world impose the requirement that they not be detrimental to the overall stability of the electric power systems. One way of ensuring this is to require RES to play a role not only in energy production but also in the delivery of ancillary services that are needed to ensure stability at both the transmission and distribution levels. Definitions of ancillary services can differ significantly [27]. Although some definitions emphasize the importance of ancillary services for system security and reliability, others mention the use of ancillary services to support electricity transfers from generation to load and to maintain power quality. Further, some definitions limit the contribution of ancillary services to the transmission network; others include distribution purposes as well. According to [28], ancillary services can be defined as all grid-support services 
required by a transmission or distribution system operator to maintain the integrity and stability of the transmission or distribution system as well as power quality. Further, the amount of ancillary services needed for power systems in the future will increase with high shares of RES.

As grid-connected RES technologies are achieving significant penetration levels, interest in analyzing the potential impacts of RES on the electric distribution grid is also increasing [29]. The primary focus of VRE, such as wind and PV, had been on the provision of energy. Early on, because most types of renewable generation were connected to the medium-voltage system, the corresponding distribution grid codes that applied treated these renewables comparable to loads (in this case "negative loads") that had to be disconnected from the grid as fast as possible in the case of disturbances [30]. A gradual change in thinking began in 2001 when the German transmission system operator (TSO) E.ON Netz published a grid code [31] that required wind power plant operators to ride through disturbances and to provide additional functionality (in addition to feeding in power) to support the operation of the conventional power stations. These functionalities included the provision of reactive power, the remote controllability of active and reactive power, the capability to keep operating after grid faults, and the capability to perform frequency down-regulation (e.g., to reduce the active power output in the case of an increase in frequency).

Today, such capabilities are usually referred to as ancillary services, and examples can be found in the literature-e.g., the authors of [32] focused on PV production for residential applications, and the authors of [33] analyzed intermittent wind resources. Indeed, with an aim toward maintaining continuity and security in electricity supply, most countries with increasing penetration levels of RES have developed specific requirements to connect them to the grid (also known as a grid code). Grid codes aim to avoid undesired disconnection under the presence of disturbances-mainly voltage dips-and they establish rules and limits for the active and reactive power as well as expected performance under frequency and voltage oscillations. These requirements have mainly focused on wind power plants [34] due to their major presence in current power systems. In fact, annual wind power installations in the European Union have increased steadily during the past 12 years-from 3.5 GW in 2000 to 11.2 GW in 2013, with an average annual growth rate of $11 \%$. PV generation has become the third most important renewable source, after hydropower and wind power. Its growth has been considerably high 
during the last few years. For example, at the end of 2009, cumulative installed PV capacity in the European Union was approaching $17 \mathrm{GW}$, and one year later it accounted for approximately 30 GW. In 2013, more than 136.7 GW of PV generation were installed globally-an amount capable of supplying at least 77 TWh of electricity every year [35]. Nevertheless, and despite the relevant presence of PV power plants in current power systems, few countries have developed specific technical requirements for these installations and their performance under disturbances. Usually these requirements have been quite similar to those for wind power plants, with the exception of the German Grid Code, which refers to technical guidelines and requirements specifically for the interconnection of PV [36].

Note that despite the increasing RES installations, the conceptual priority of RES in current grid codes is not to replace conventional generation but primarily to reduce consumption. This may be seen as a question of wording only, but with respect to the requirements this has a significant impact. For a long period of time, "negative loads" such as RES were considered to behave like typical loads connected to a distribution system-i.e., they should limit the impact on the grid by having a predefined power factor range and disconnect in the case of grid events such as relevant changes in voltage magnitude, voltage phase angle, or frequency.

Largely resulting from pressure by TSOs, requirements for RES-even those connected to a distribution system-usually try to limit their impact on the grid. Features such as the capability to support the grid are often referred to as RES being "grid friendly," and they are necessary to reduce possible impacts on the grid in the case of disturbances; however, note that these features always assume a stable grid consisting of a sufficient number of synchronous generators in operation that ensure basic services such as voltage stability (by providing voltage control and sufficient short-circuit power) and frequency stability (by providing primary control and system inertia). Today's grid code requirements describing ancillary services are not intended to replace the basic services provided by conventional power stations. Also, today's RES are neither allowed (by grid codes) nor capable (due to existing control and hardware design) to provide these services. The development of a next generation of RES that may provide such features on a larger scale (not only for a small, islanded system) is only beginning. 


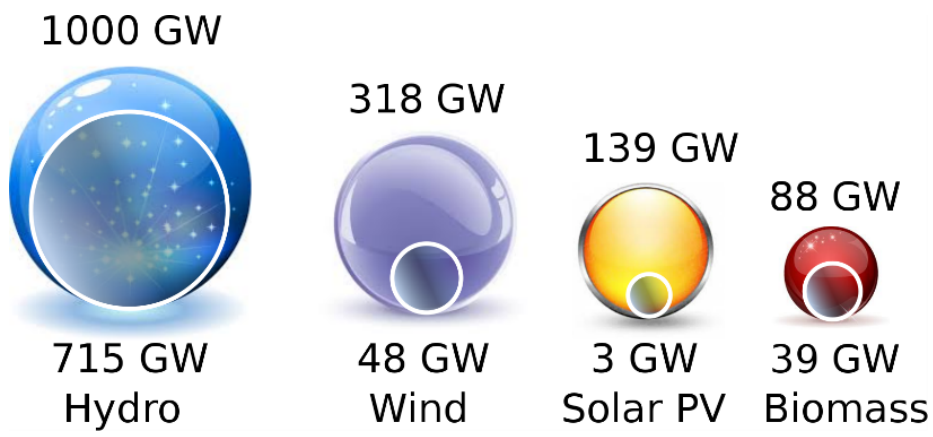

Figure 3: Net generation capacity added in 2000-2013 [9]
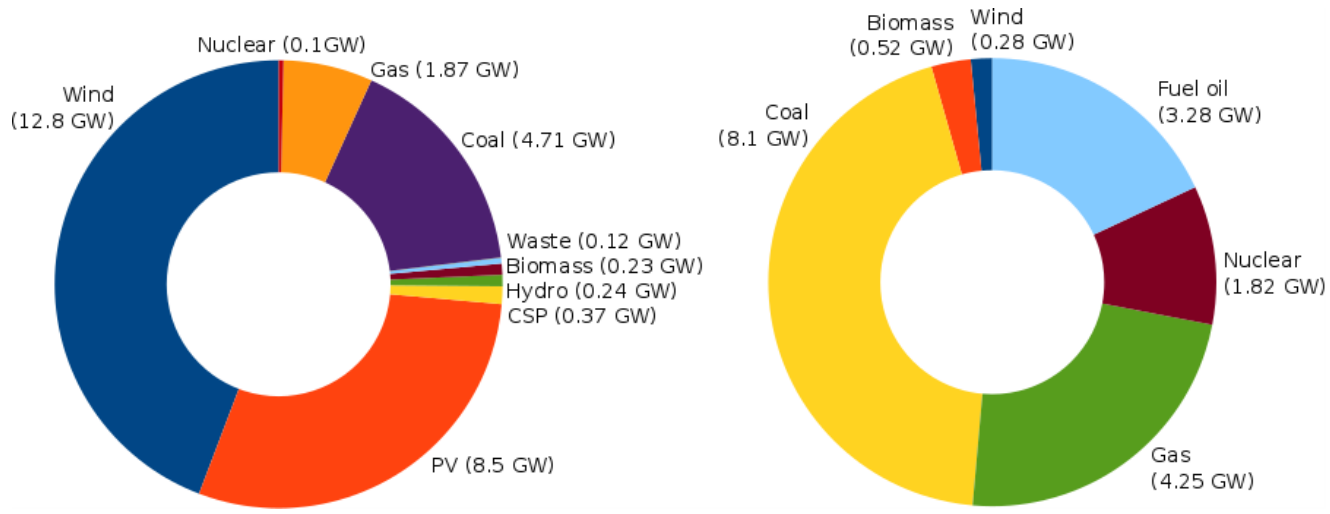

Figure 4: New installed and decommissioned power capacity at the end of 2015 in the European Union [17]
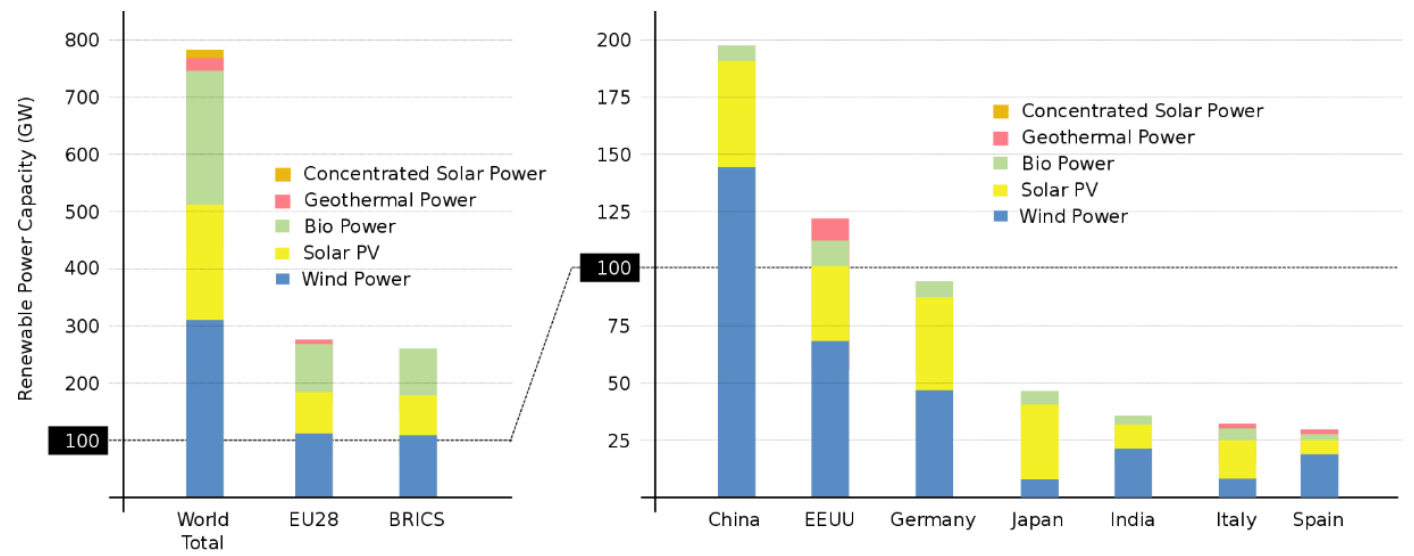

Figure 5: Renewable power capacity at the end of 2015 in the world, the 28 member states of the European Union (EU-28), the five major emerging national economies (Brazil, Russia, India, China, and South Africa; BRICS), and the top seven countries [13] 


\section{A. Active Power Reserves and Frequency Control}

Frequency control services are related to the short-term balance of energy and frequency of a power system. According to the definition by the Union for the Coordination of the Transmission of Electricity [37], frequency control includes automatic (primary/secondary) and manual (tertiary) frequency regulation and operating reserves, as illustrated in Figure 6. This is the main service provided by generators (online for automatic services and online or offline for longerterm activated services). It can also be provided from flexible loads and storage units.

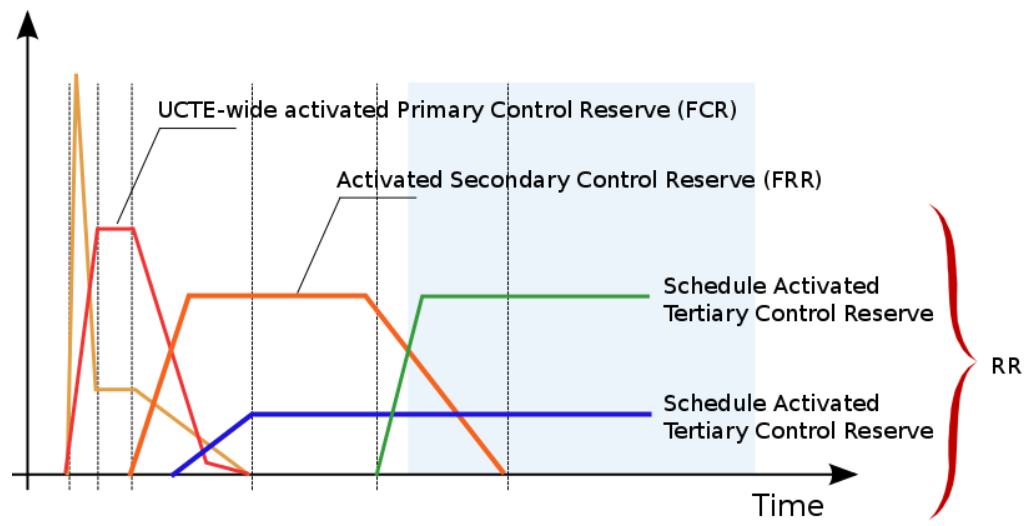

Figure 6: Principal frequency deviation and subsequent activation of reserves [38]

According to the ENTSO-E classification [38], frequency control reserves are defined as frequency containment reserves, frequency restoration reserves, and replacement reserves; see Figure 6 . In Denmark, the TSO (Energinet.dk) published an ancillary services strategy for 2011-2015 [39] that classifies the ancillary services into frequency-controlled reserves, secondary reserves, manual reserves, and regulating power and properties required to maintain power system stability (e.g., short-circuit power, continuous voltage control, voltage support during faults, and inertia).

Recently, a demonstration project was conducted by the National Renewable Energy Laboratory in collaboration with Puerto Rico Electricity Power Authority (PREPA) to demonstrate the ability of a PV power plant to operate in spinning reserve mode by curtailment. Puerto Rico's transmission system consists of $230-k V$ and $115-k V$ lines, 38-kV subtransmission lines, and 334 substations. PREPA's typical summer daytime peak load is approximately $2.8 \mathrm{GW}$. Total installed generation in 
the region has a capacity of $6 \mathrm{GW}$, with $173 \mathrm{MW}$ of wind and PV generation; the rest is based on petroleum and natural gas. AES's 20-MW Ilumina PV power plant, located in Guayama, Puerto Rico, consists of 40 inverters rated at $500 \mathrm{kWac}$ each. Several solar irradiance sensors are placed strategically within the PV plant, and they are used to forecast the actual output of the PV plant. Based on the real-time forecast of the plant output, supervisory control is used to curtail the output of the PV plant partially by $20 \%$ (and subsequently $40 \%$ ) to operate the PV plant with a spinning reserve of $20 \%$ from the maximum available power generation. The frequency control is demonstrated by the implementation of both the droop control and the automatic generation control. The demonstration projects were implemented successfully, as reported in [40].

\section{B. Reactive Power Control/Voltage Control}

From a system point of view, voltage is the prerequisite for any kind of power transport. By changing the amount of reactive power provided to a grid (by changing the reactive power reference of power stations and active or passive sources), the power flow in the grid can be controlled. In most countries, RES play only a very limited role in controlling the voltage of transmission systems.

\begin{tabular}{|c|c|c|c|c|c|c|}
\hline & UK & Spain & France & Germany & Nordel & USA \\
\hline 1.20 & \multirow{8}{*}{ Always } & $0.05-1 \mathrm{~s}$ & & \multirow{3}{*}{$30 \mathrm{~min}$} & & \\
\hline 1.15 & & $15 \mathrm{~min}$ & & & & \\
\hline 1.115 & & 1 hour & & & & \\
\hline 1.10 & & \multirow{5}{*}{ Always } & $5 \mathrm{~min}$ & \multirow{4}{*}{ Always } & 1 hour & \\
\hline 1.05 & & & \multirow{3}{*}{ Always } & & \multirow{4}{*}{ Always } & \\
\hline 1 & & & & & & Always \\
\hline 0.95 & & & & & & \\
\hline 0.90 & & & \multirow{3}{*}{$90 \mathrm{~min}$} & 2 hours & & Contingency \\
\hline 0.875 & & 3 hours & & & & \\
\hline 0.85 & & $30 \mathrm{~min}$ & & & 1 hour & \\
\hline 0.80 & & & Variable & & & \\
\hline
\end{tabular}

Figure 7: Voltage deviation and subsequent activation of reserves [41]

At the level of the distribution system, voltage control services focus on maintaining power system voltage within the prescribed bounds during normal operation and during-and especially following-disturbances by keeping the balance between generation and consumption of reactive power. Voltage control includes reactive power supply (injection or absorption), and it can be provided by dynamic sources (generators, synchronous compensators) and static 
sources (capacitor banks, static voltage controllers, and FACTS $^{1}$ devices), including network equipment such as tap-changing transformers in the substations and loads. Voltage control has two targets:

- Steady-state reactive power/voltage control: The aim is to keep the voltage profile close to the desired profile and within the tolerance band margins within the time frame of hours. This control is commonly achieved by injecting or absorbing reactive power at a voltagecontrolled node. The TSO dispatches the reactive power using the active and passive reactive power sources that belong to different levels - generation, transmission, and distributionusing optimal power flow methods. Steady-state requirements are usually defined as power factor or voltage requirements at the level of a wind power plant, with typical response times in the range of seconds up to one minute. The integration of RES power stations into a power system has usually been facilitated with economic incentives. This is the case of reactive power generation. For example, in Spain in 2004 the Royal Decree 436/2004 introduced an incentive as a percentage of the average reference tariff. In 2007, a new incentive for reactive power was also introduced in Spain, IV.02, which had a scheme similar to that of the previous incentive. It is based on a reference value that is updated based on the Consumer Price Index minus a correction value. In this new scheme, hourly values are used instead of quarterhourly ones, and dispatches are introduced. This change was because dispatchers seek results at the wind power plant's point of interconnection, but measurements are performed at the level of the wind power plant's substation. The values (cent $€ / \mathrm{kWh}$ ) from these two schemes were 7.659 and 7.8441 in 2006 and 2007, respectively. This power factor incentive was suppressed in Spain in 2013.

- Dynamic voltage stability: The aim is keep the network voltages in a dynamic time frame (seconds to minutes), thus preventing a slow voltage collapse event or limiting the depth and extension of an incident (e.g., loss of a main line, loss of generation unit). Dynamic voltage requirements are usually defined as reactive current response at the turbine level, with typical response times in the range of 30-50 ms.

In traditional power systems, VRE proportion has been considered very small relative to conventional generating units. As the penetrations of RES increase-especially wind and solargrid codes compel renewable generation to contribute more significantly to power system

\footnotetext{
${ }^{1}$ Flexible alternating current transmission system
} 
voltage and reactive regulation [43]. Starting in 2006 [44], the capability to provide ancillary services, such as (limited) frequency control and voltage control, has become a requirement in grids that have a high penetration level of renewables. Nevertheless, knowledge gaps-especially at the level of distribution system operators - and thus the need for further research have been identified in the area of the provision of ancillary services from RES. For example, according to [43], in the context of ancillary services delivered from wind power plants, further investigations strengthening system reliability are necessary regarding faster and reliable communication (i.e., among wind power plants and system operator control rooms), dedicated tuning of the control strategies, estimation of available power, and coordination of offshore wind power plants to provide reactive power control or voltage control at their land-based point of coupling. In the context of ancillary services delivered from PV, further investigations are needed on available (regional) power estimation, faster and reliable communication and control within the plants, and improved control strategies.

Grid code design depends a lot on the knowledge of the system operator and the size of the wind power plant. In the United States, large wind power plants interconnected to the transmission system are common, and as a result they are treated as power stations based on synchronous generators using classic (PI) voltage control. Power factor control is usually not allowed. In case the short-circuit power of the grid is considerably higher than the reactive power capability of the wind power plant, pure P-control of the voltage is used ("voltage static") instead of a PI control. This is necessary because the reactive power capability of the wind power plant is too small to really control the voltage, and the controller of the wind power plant would be saturated. (See also [46] as an application in Europe.) In case a wind power plant is too far from the highvoltage grid, voltage excursions can be significantly limited if voltage control is used. In the case of short-circuit ratios (i.e., the grid's short-circuit power divided by the wind power plant's apparent power) of 5 and lower, usually voltage control is needed to keep the voltage within the normal operating range ([47], [48], [49]). In the United Kingdom, a proportional voltage control ("voltage static") is commonly used. In Germany, power factor control had been common, but due to the improved voltage-stabilizing capability of voltage control, voltage static at the level of the wind power plant is becoming the preferred method of control for newer, interconnected, medium-voltage wind power plants. 


\section{RES UNDER DISTURBANCES: FAULT RIDE-THROUGH CAPABILITY}

With increasing penetration levels of renewable energy in power systems, mainly due to the integration of wind power plants, more responsibilities must be assumed by the wind power plants to support power system reliability [50]. In fact, before the fast increase of such distributed generation units at the low-voltage and medium-voltage levels of a grid, system operators traditionally controlled the grid through conventional power plants. This practice changed when significant amounts of wind and PV were integrated into the systems, and consequently renewables needed to be considered in planning and operating the grid [51]. For this reason, grid code requirements have been extended to low-voltage ride-through (LVRT) capability, which demands that generation units, including renewable power plants, stay online and supply a specified amount of reactive current to stabilize the voltage during faults.

\begin{tabular}{|c|l|}
\hline $\begin{array}{c}\text { Connection } \\
\text { Codes }\end{array}$ & $\begin{array}{l}\text { - Generator Connection Code } \\
\text { - Demand Connection Code } \\
\text { - HVDC Connection Code }\end{array}$ \\
\hline $\begin{array}{c}\text { Operating } \\
\text { Codes }\end{array}$ & $\begin{array}{l}\text { - Operational Security Code } \\
\text { - Operational Planning and Scheduling Code } \\
\text { - Load Frequency Control and Reserve Code } \\
\text { - Emergency Procedure Code }\end{array}$ \\
\hline $\begin{array}{c}\text { Planning } \\
\text { Codes }\end{array}$ & $\begin{array}{l}\text { - Generator Planning Code } \\
\text { - Network Planning Code }\end{array}$ \\
\hline Market & $\begin{array}{l}\text { - Market Rules Code } \\
\text { - Network Capacity Allocations and } \\
\text { Congestion Management Code }\end{array}$ \\
\hline
\end{tabular}

Figure 8. Different types of grid codes based on ENTSO-E [23]

Generally, LVRT defines steady and dynamic performances of the renewables in three continuous periods after a grid fault occurrs: fault transient, fault continuous, and fault recovery [52], [53]. According to [54], fault ride-through requirements should be extended to smaller generation units mainly due to the following aspects:

- Future generation systems will be based on a vast number of distributed, power electronicsbased generators and RES that are variable and only partly dispatchable.

- To a significant extent, RES are connected to the distribution network.

- The objective is to proportionally allocate the requirements for future generators throughout Europe on a level playing field. 
- It is of increasing importance that a single system event should not result in a large-scale shutdown of generation. RES generators needs to be resilient to system faults by staying connected (and generating) during the initial voltage transients (as conventional generators do today).

Grid codes, in the widest set of the term, involve a set of rules for power system and energy market operation. They enable network operators, generators, suppliers, and consumers to function more effectively across the market. Different types of grid codes are depicted in Figure 4. Grid code requirements under voltage dips have typically been expressed as a function of positive-sequence voltage against time.

This is the case for current requirements for wind power plants submitted to voltage dips, which vary significantly from one country to the next, depending on the penetration level of the renewable technology as well as on the robustness of the national or regional power system. There is considerable variation even within the European Union [56], although standardization is being implemented [38]. In Europe, countries that have high renewable power capacity, such as Germany and Spain, first developed specified requirements to ensure the continuity of the supply side in the presence of disturbances, mainly voltage dips, and connection and continuity requirements for RES are becoming more demanding. Figure 9 summarizes the current grid code requirements provided by most European countries for wind installations connected to the grid. In all cases, if the rms voltage trajectories remain above the minimum voltage limits, the generating units shall remain transiently stable and connected to the system, without tripping a close-up, solid, three-phase, short-circuit fault or any unbalanced short-circuit fault on the transmission system [57]. In [58], the problem of testing power electronics and control systems through a finite set of conceivable fault voltage waveforms is addressed by setting forth a powerful computational technique for the design verification of wind turbine power electronic drives, and computational technique for design verification has been proposed by [59].

The industry standard for wind turbine testing is the International Electrotechnical Commission (IEC) Standard 61400-21 [60], which describes the test procedures for active power, reactive power, and fault ride-through testing. IEC 61400-27 [61] describes the corresponding generic simulation models and verification procedures for mode validation. 


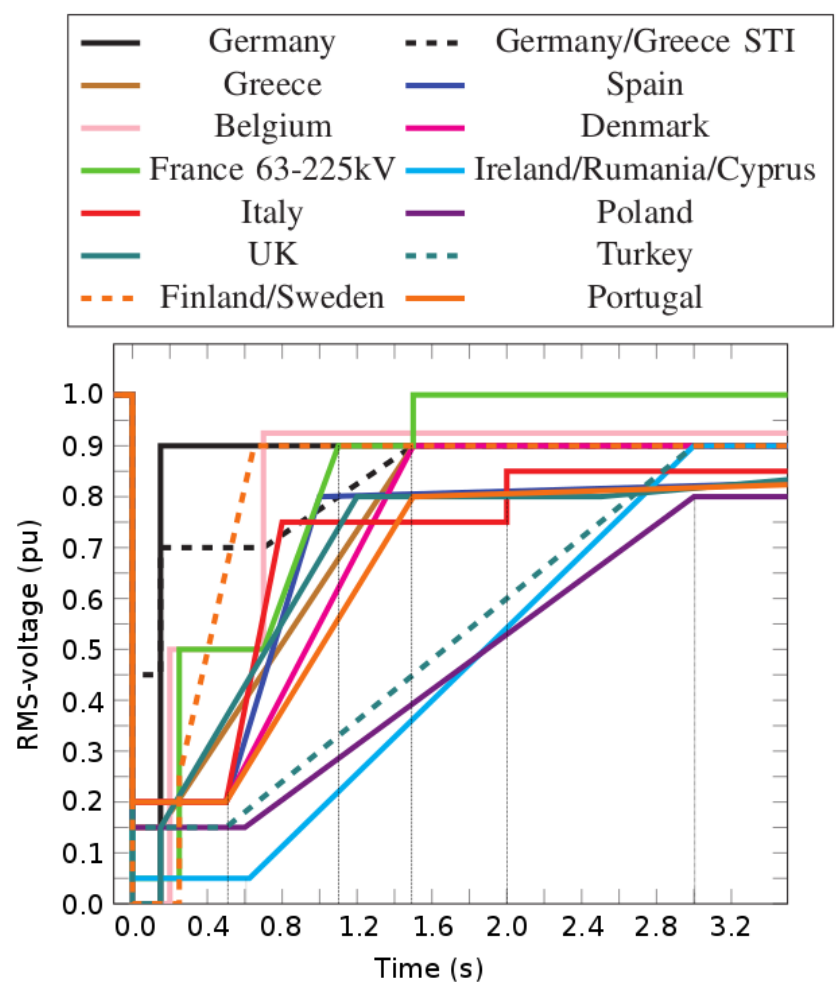

Figure 9. Grid code requirements of wind power plants: comparative of rms-voltage-limiting curves at the point of interconnection [55]

As variable generation units, PV power plants may lead to possible stability problems in power systems. Moreover, new power flow patterns should be studied in detail to evaluate the impact of high PV penetration on current electric grids [62]. In this context, and to avoid potential drawbacks associated with undesired PV power plant disconnections, TSOs have promoted strict technical requirements for RES connected to the grid and submitted to disturbances. Recent reports have focused on providing preliminary overviews about the risks for system stability caused by the disconnection of dispersed generation in case of over- or underfrequency events [63]. Different examples of grid code requirements can be found in various countries in Europe, such as Spain, Germany, and Italy. These countries have the biggest capacities of PV panels installed in Europe. The Spanish TSO (REE), as system operator of the national grid, developed the operation procedure Requirements for Response to Voltage Dips of Production Facilities under the Special Regime (P.O.12.3) [64]. These requirements were approved and issued in October 2006, and only wind power plants were called on to fulfill the specific requisites under the presence of such disturbances. In November 2010, the RD 1565/2010 was proposed and issued [65], supposing an extension of the previous continuity requirements to PV power plants in response to voltage dips. In German, in 2008 BDEW published the Technical Guideline: Generating Plants Connected to the Medium-Voltage Network- 
Guideline for Generating Plants Connection to and Parallel Operation with the Medium-Voltage Network [66]. This revised version of the German grid code proposes two types of generation power plants-type-1 and type-2-depending on their performance under disturbances: type-1 includes generating plants wherein synchronous generators are either directly connected to the grid or only through the generator transformer; whereas the rest of the power plants-including RES-are classified as type-2. The general rules in Italy can be summarized in the following reports: CEI 0-16 (which references technical rules for the connection of active and passive consumers to the high-voltage and medium-voltage electrical networks of distribution companies), CEI 11-20 (which discusses electrical energy production systems and uninterruptible power systems connected to the low-voltage and medium-voltage networks), and CEI 1132 (which discusses electrical energy production systems connected to the high-voltage network). CEI 0-21 discusses the technical requirements for the interconnection of PV power plants. European grid codes thus present specific criteria for the interconnection of PV power plants and their performance under disturbances. In an attempt to compare these different requirements, Figure 6 shows the voltage-rms limitations for PV power plants at the point of interconnection. Both magnitude and the duration of the voltage dips according to the different European grid codes are depicted, characterizing the severity of their requirements and emphasizing their differences. These differences are pointed out by some authors as major obstacles to the deployment of distributed energy renewable sources, such as PV [67], [68]. Today, in an attempt to establish general rules to which new generators must adhere, the latest draft of the Network Code on Requirements for Generators (provided by ENTSO-E) gives guidance on the implementation processes for all generators wishing to connect below $110 \mathrm{kV}$ and within the European Union; see Figure 10 and Table 1. Most developed countries are carefully observing the development of growing installed capacities and promoting initiatives to develop new disconnection rules for PV panels based on system requirements. These requirements need to be in line with the current draft version for the ENTSO-E network code. In general, contributions including both characterization and classification techniques for power disturbances can be found in [69], [70], [71]; however, only a few contributions present power quality surveys of renewable power installations [72], [73], [74], [75]. 


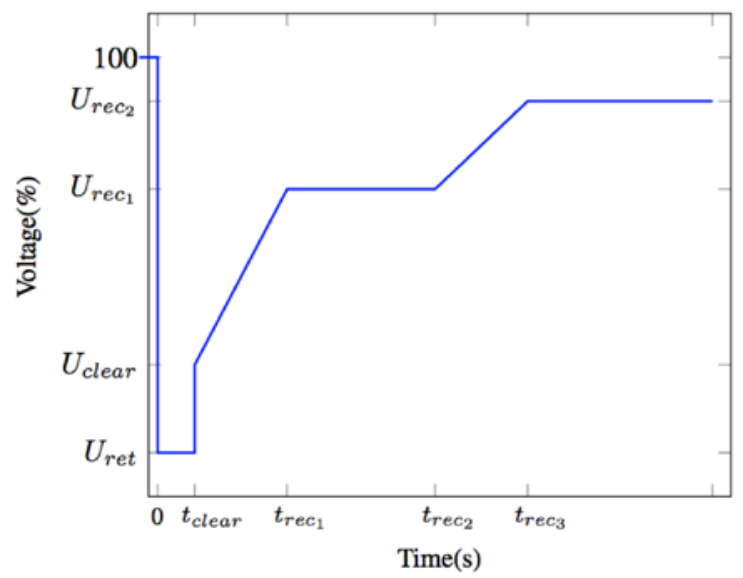

Figure 10. Guideline for grid code requirements: voltage-limiting curves for generating units at the point of interconnection [38]

TABLE I

GUIDELINEd FOR GRID CODE REQUIREMENTS: PARAMETERS FOR TIMES AND VOLTAGES WITHIN RANGES DEFINED BY THE NETWORK CODE [38] Synchronous Power Generating Modules Power Park Modules

\begin{tabular}{|c|c|c|c|c|c|c|c|}
\hline \multicolumn{2}{|c|}{ Voltage parameters (pu) } & \multicolumn{2}{|c|}{ Time parameters (sec) } & \multicolumn{2}{|c|}{ Voltage parameters (pu) } & \multicolumn{2}{|c|}{ Time parameters (sec) } \\
\hline Uret & $0.05-0.3$ & tclear & $\begin{array}{l}0.14- \\
0.25\end{array}$ & Uret & $0.05-0.15$ & $t_{\text {clear }}$ & $\begin{array}{l}0.14- \\
0.25\end{array}$ \\
\hline$U_{\text {clear }}$ & $0.7-0.9$ & $\operatorname{trec}_{1}$ & $t_{\text {clear }}$ & $U_{\text {clear }}$ & $U_{\text {ret }}-0.15$ & trec1 & $t_{\text {clear }}$ \\
\hline Urec 1 & $U_{\text {clear }}$ & trec2 & $t_{r e c 1}-0.7$ & $U_{\text {rec } 1}$ & $U_{\text {clear }}$ & trec2 & trec1 \\
\hline Urec2 & $0.85-0.9$ and $U_{\text {clear }}$ & trec3 & trec2 -1.5 & $U_{\text {rec } 2}$ & 0.85 & trec3 & $1.5-3.0$ \\
\hline
\end{tabular}

However, there is a lack of contributions focused on comparing real voltage dips to current requirements and estimating how severe and close to the rms-voltage limits the collected events are. According to the specific literature, representations usually reduce the analysis of events in terms of two main characteristics: minimum rms-voltage compared to time duration. These studies imply an important simplification of disturbances, neglecting the rms-voltage evolution during the event. In fact, apart from the residual rms-voltage, the severity of the faults is highly dependent on the voltage evolution along the disturbance as well as the point-on-wave initiation [76]. Therefore, a comparison between rms-voltage limits and real voltage dips based on the entire rms-voltage dip trajectory versus time initially appears to be more appropriate, and it is proposed by several authors as a relevant field of study for future work. 


\section{Renewable Energy Curtailment}

Increasing wind and solar penetration levels may drive a power system to encounter transmission, distribution, or operational constraints, forcing the TSOs to take into account the performance of these spatially distributed renewable power plants [77]. Therefore, high levels of wind and solar power generation can be challenging to integrate into power systems because of their variability [78] and limits in predictability, leading to use curtailments, or less wind or solar power than is potentially available at that time [79], [80], [81]; however, curtailment of power stations has been a normal practice since the beginning of the electric power industry [82]. Taking into account the constraints imposed by flexibility in a specific power system, different solutions can be used to accommodate variable generation during these situations [83], such as dispatchable power plants, energy storage, interconnection capacity, or demand-side response [84]. The need for energy curtailment for variable generation is applied during a limited time, or transition phase, before some changes can be programmed to the grid-infrastructural, operational, or institutional. Even interannual oscillations in variable generation should be taken into account. Figure 11 shows the influence of the month on the global variable power generation in Spain, taking into account three typical technologies: wind, PV, and CSP. Data clearly show variability in the months and among the years.

There are many reasons for RES curtailment, including lack of transmission and distribution availability or system balancing challenges. Moreover, RES curtailment is a very complex issue because the coincidence in the time of the curtailment, network thermal congestion, or systemwide inertial stability problems carry out to the interaction among different sources of curtailment [85]. The main reasons in power systems with very high wind energy penetration targets are related to the lack of available transmission during a particular interval to incorporate some or all of the variable generation and system balancing issues [86]. In [87], a comparison of different levels of curtailment takes into account variable energy penetration ratios in selected countries/areas. For example, in the United States the Electric Reliability Council of Texas achieves upward primary frequency reserves from curtailed wind generation. The value of these ancillary services implies that curtailment does not need to be seen as a waste of energy. China can be considered an extreme example, because in 2013 approximately 16.23 TWh of wind 
generation was curtailed ( $10.74 \%$ of total wind generation), and this value was even an improvement from the 20.82 TWh curtailed in 2012.

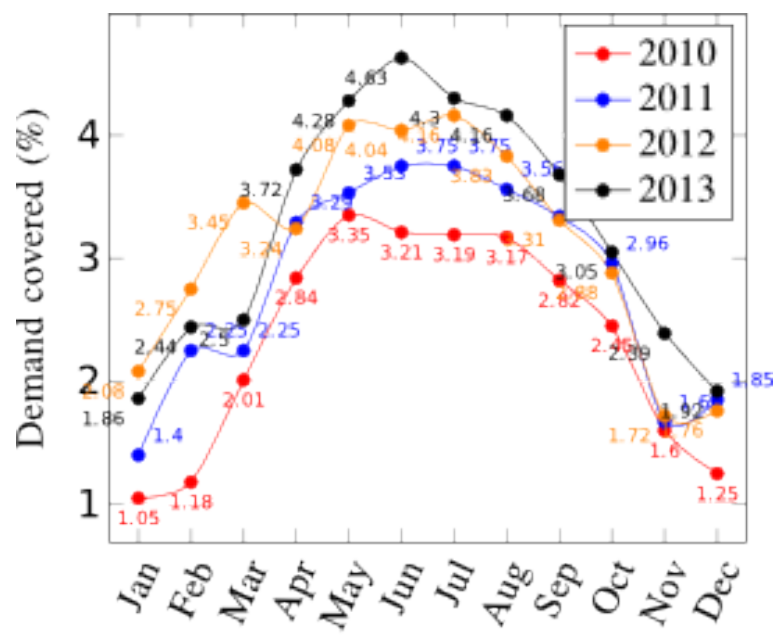

Month

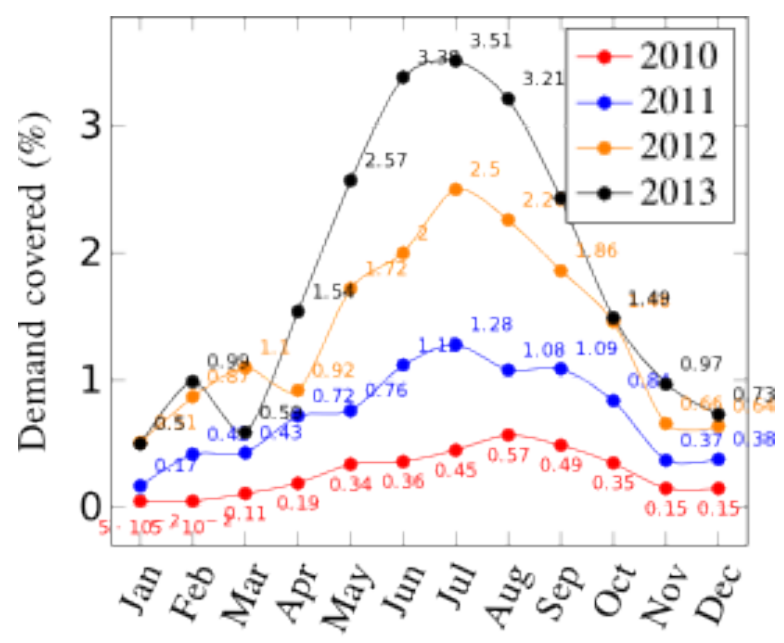

Month (a) Solar PV generation

Month

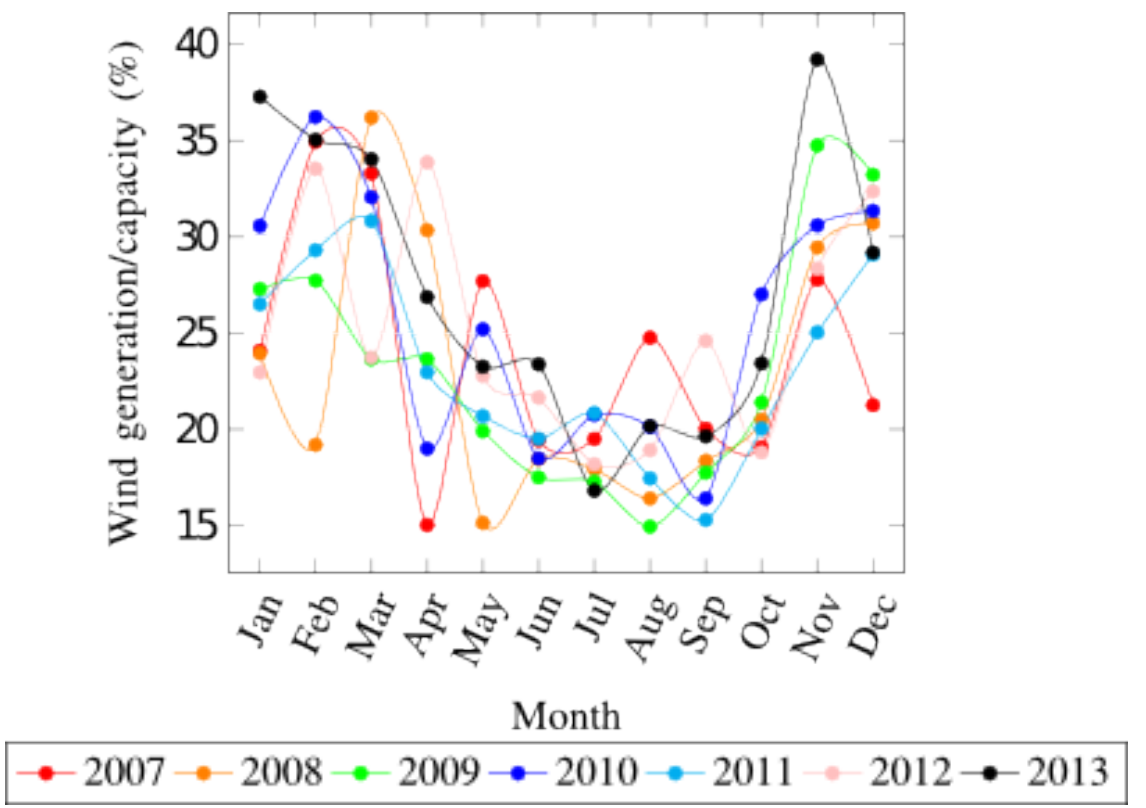

(b) CSP generation

(c) Wind generation

Figure 11: Variable generation in Spain 
Transmission congestion is usually related to the development timescales of variable generation power plants. They can generally evolve much more quickly than the new required transmission projects, leading to a timing mismatch in construction between wind development and new transmission [88]. It may take 5-10 years to plan (or more, depending on the country), permit, and construct a transmission line, whereas a wind or solar project can be planned, permitted, and constructed in 1-3 years [88], [89], [90]. System balancing issues typically occur with high wind generation at night, when loads are low and thermal units are pushed down against their minimum operating constraints, and the generation excess cannot be exported to other balancing areas due to transmission constraints [91]. In some countries, such as Spain, variable generation, mainly wind, may be curtailed after other power plants are pushed down against their minimum operating constraints, reducing or even removing power imports reduced. The low capacity factor of variable generation and the uncertainty and variability associated with it, together with the system flexibility, are the main reasons for this kind of curtailment [84]. In countries with large amounts of wind power, this issue could be regulated somehow. For Spain's power system, this kind of curtailment is referred to in the Non-Integrable Wind Power Excess and is defined in the Operational Procedure 3.7 [92]. On the other hand, in the distribution system, curtailment can occur to avoid high penetrations or back-feeding, in which more energy is produced at the feeder level than consumed. In some cases, high penetrations of solar PV generation on feeders can lead to voltage control issues due to the variability of the resource [93].

Curtailments can be related to other reasons as well, such as grid stability and short-circuit power, mainly due to disturbances and voltage dips affecting the network. Such curtailment measures though are more likely to be observed in small, isolated systems, such as Ireland [94]. It has been identified that higher, instantaneous system, nonsysnchronous penetration levels may require wind power curtailment, unless no other measures to maintain the system stability are considered. In many countries this issue is partially solved due to the fact that most wind power plants and solar PV power converters can support LVRT [94]. In Spain, approximately 95\% of wind generation is certified under LVRT requirements, and therefore curtailment due to voltage dips has not been an issue since 2009. 
In Spain, curtailments can be classified, according to market procedures, in two categories: real time and programmed. Real-time curtailments are obtained from the intraday markets. On the other hand, programmed curtailments are set before the day-ahead market is closed (Basic Operation Program, PDBF). The former is partially compensated as a function of daily market price, and the latter is not economically compensated [96]. In the case of wind generation, in Spain set points due to real time curtailments are calculated and delivered-through the Control Centre of Renewable Energies (CECRE) - with maximum wind nodal production, and wind power plants affected must adapt their production to the given set point within 15 minutes. CECRE is an operating unit within the power control center (CECOEL) that is connected to $98.6 \%$ of installed wind power capacity in Spain, whereas the remaining wind power $(1.4 \%)$ is estimated. CECRE has been in operation since 2006, and it is considered a worldwide pioneering initiative to monitor and control renewable power plants, specifically wind power plants. CECRE does not telecommand generation equipment; this function is done by generation control centers. The telecommunication deployment of almost 800 wind power plants has been accomplished by aggregating power stations larger than $10 \mathrm{MW}$. Measurements such as active and reactive power, voltage, connectivity, temperature, and wind speed and wind direction are taken from wind power plants every 12 seconds and sent to a Renewable Energy Resource Control Centre (RESCC).

TABLE II

WIND GENERATION AND CURTAILMENT DATA BY COUNTRY (2013) [79]

\begin{tabular}{lrrrrrr}
\hline Country & China & Germany (2012) & Ireland & Italy & Spain & United States \\
\hline $\begin{array}{l}\text { Electricity generation } \\
\text { (TWh) }\end{array}$ & 5372 & 577 & 26 & 290 & 284 & 4066 \\
\hline Wind generation (GWh) & 142,000 & 50,600 & 5872 & 14,811 & 54,338 & 167,840 \\
\hline Wind/electricity generation & $2.6 \%$ & $9.8 \%$ & $22.5 \%$ & $5.1 \%$ & $19.2 \%$ & $4.1 \%$ \\
\hline Wind curtailment (GWh) & 16,230 & 358 & 196 & 152 & 1166 & - \\
\hline $\begin{array}{l}\text { Wind } \\
\text { Curtailment/generation }\end{array}$ & $11 \%$ & $0.7 \%$ & $3 \%$ & $1 \%$ & $2 \%$ & $1-3 \%$ \\
\hline
\end{tabular}


Curtailment data during 2013 for different countries are shown in Table 2 [79]. Wind curtailment typically ranged from approximately $1 \%-3 \%$ of wind generation levels, although China exceeds this range, getting $11 \%$. The implementation of curtailment in a power system is a complex issue because under certain conditions some events can produce severe deviations from the original set points of the TSO. In [94], a curtailment event with an overresponse in the level of the curtailment is described. It is shown that the Spanish TSO imposed different set points by taking into account the Non-Integrable Wind Power Excess. This example occurred in January 2010, and the final curtailment due to the overresponse in the wind power generation was more than four times the wind power curtailment originally required. Although this type of event could be classified as exceptional, the operation of the power system can be put at risk, even with from an economic point of view, because upward reserves are used for balancing, which increases the associated costs. Therefore, the evolution of the flexibility exhibited in the power system is related to the level of curtailment applied to variable generation. An example of this relationship is shown in [96] using the parameter, $P_{\text {flex1, }}$ in which values are referred to the registered values during a year. Two case studies representing curtailments in wind generation in two situations are examined: low power demand (off-peak periods) and high wind power contribution in the first case, and during high wind power forecast error stages in the second case.

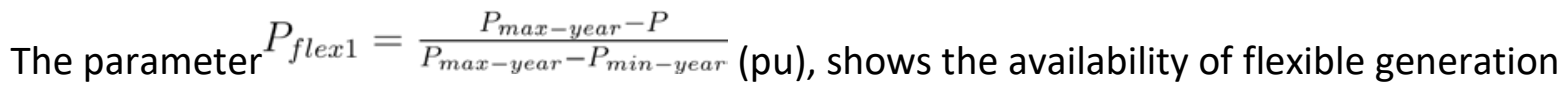
during the curtailment compared to the ordinary power system operation. $P_{\max \text {-year }}$ is the maximum yearly power value for that technology, $P_{\text {min-year }}$ is the minimum yearly power value for that technology, and $P$ the power value for the considered time period.

Figure 12 shows the evolution of generation-wind and nuclear power-during Easter 2013. On March 31, due to the large amount of wind generation in conjunction with the significant amount of rainfall, saturation of the hydraulic reserves occurred. Moreover, due to the holiday season, this is one of the periods of the year with lower power consumption. So reserves for the pumped storage hydropower could not be used, and most of the hydraulic power plant became unmanaged. The result was a huge amount of curtailment in wind generation, reducing at the same time the nuclear generation, approximately 1,000 MW; see Figure 12c. The evolution of the flexibility in the power system is shown in Figure $12 \mathrm{~b}$, wherein eight steps are considered, taking into account the flexibility imposed by the hydropower generation, pumped hydropower 
generation, combined-cycle gas turbine, and the demand, together with the international imported/exported electricity. The figure clearly shows the evolution of $P_{f l e x}$ with changes in the hydropower generation together with the international import/export. This phenomenon has occurred several times in Spain, although not as severe, due to the explosive cyclogenesis and heavy rainfall combined with high wind production; therefore, increasing the flexibility of the system is the best way to reduce curtailments. The methods of increasing system flexibility depend on the power system, with different possibilities taking into account the proportions of each method [97], [98], [99]. The main ones are grid capacity, physical additions to the system (such as storage or new transmission lines [100], [90]), power system operational changes (such as economic dispatch or improved forecasting [102]), and institutional changes (such as access to new markets [102]).

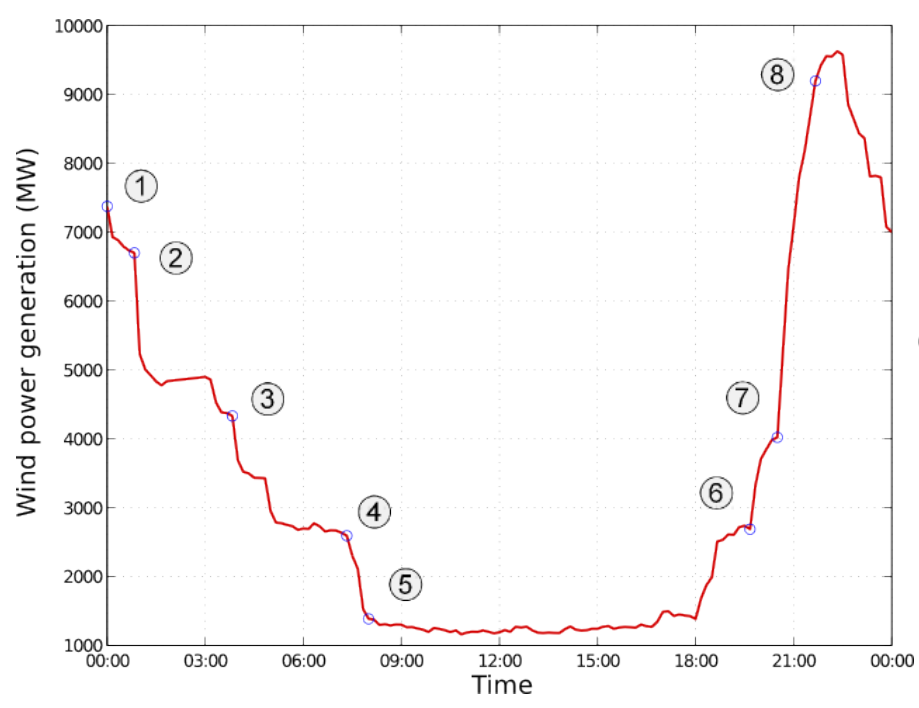

(a) Wind power generation

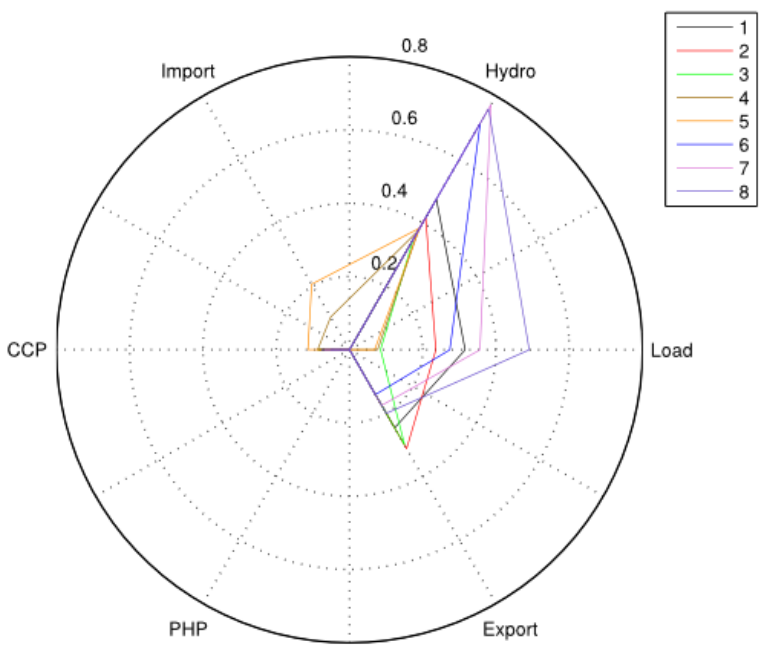

(b) Flexibility evolution 


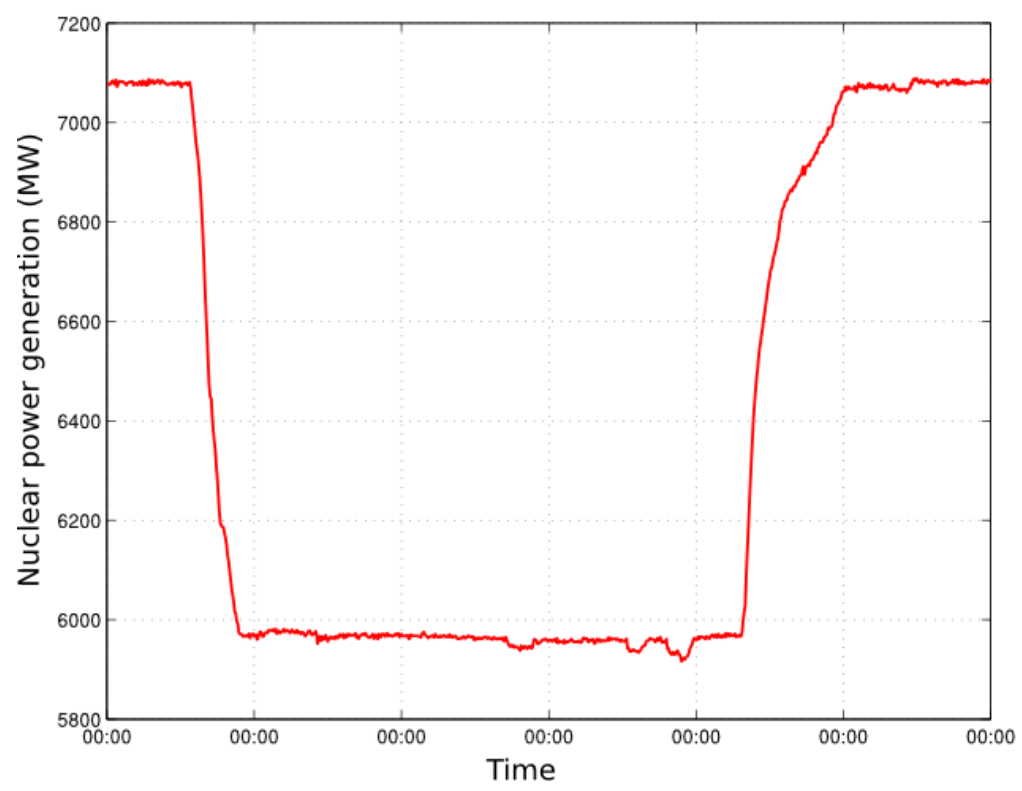

(c) Nuclear power generation

Figure 12: Evolution of wind and nuclear power generation during Easter 2013 in Spain 
ACKNOWLEDGMENTS

The authors would like to thank the "Ministerio de Economía, Industria y Competitividad" and the European Union FEDER, which supported this work under project ENE2016-78214-C2-1-R. This work was supported by the U.S. Department of Energy under Contract No. DE-AC3608GO28308 with the National Renewable Energy Laboratory. Funding provided by [applicable DOE Office and Program, e.g., U.S. DOE Office of Energy Efficiency and Renewable Energy Solar Energy Technologies Program]. The U.S. Government retains and the publisher, by accepting the article for publication, acknowledges that the U.S. Government retains a nonexclusive, paid-up, irrevocable, worldwide license to publish or reproduce the published form of this work, or allow others to do so, for U.S. Government purposes.

\section{REFERENCES}

[1] European Union Committee, 27th Report of Session 2007-08, “The EU's Target for Renewable Energy: 20\% by 2020", October 2008.

[2] P. V. L.W.M. Beurskens, M. Hekkenberg, "Renewable energy projections as published in the national renewable energy action plans of the european member states," European Environment Agency (EEA), Tech. Rep., November 2011.

[3] International Energy Agency, World Energy Outlook 2015, Energy Subsidies [online], available at http://www.worldenergyoutlook.org/media/weowebsite/2015/Subsidies20122014.xlsx

[4] “World Energy Outlook 2012." International Energy Agency (IEA), Tech. Rep., 2012. [Online]. Available: www.iea.org

[5] J. Glassmire, P. Komor, and P. Lilienthal, "Electricity demand savings from distributed solar photovoltaics," Energy Policy, vol. 51, pp. 323-331, 2012.

[6] D. Carvalho, J. Wemans, J. Lima, and I. Malico, "Photovoltaic energy mini-generation: Future perspectives for Portugal," Energy Policy, vol. 39, no. 9, pp. 5465-5473, 2011.

[7] A. Battaglini, N. Komendantova, P. Brtnik, and A. Patt, "Perception of barriers for expansion of electricity grids in the European Union," Energy Policy, vol. 47, pp. 254-259, 2012.

[8] RENEWABLE ENERGY. Medium-Term. Market Report 2015. Market Analysis and Forecasts to 2020, IEA 2015, Available Online https://www.iea.org/Textbase/npsum/MTrenew2015sum.pdf

[9] The First Decade: 2004-2014, Renewable Energy Policy Network for the 21st Century, Available On-line http://www.ren21.net/Portals/0/documents/activities/Topical\%20Reports/REN21 10yr.pdf

[10] C. E. Behrens, "Energy policy: 113th congress issues," in Congressional Research Service, 2013.

[11] "European Commission,2010a . Energy 2020. A strategy for competitive, sustainable and secure energy." Bruselas, Tech. Report, November 2011.

[12] “Monthly electricity statistics," International Energy Agency (IEA), Tech. Rep. [Online]. Available: www.iea.org. 
[13] "Renewables 2016 Global Status Report", Renewable Energy Policy Network for the $21^{\text {st }}$ Century. [Online] Available http://www.ren21.net T. Sterner and M. Damon, "Green growth in the post-Copenhagen climate," Energy Policy, vol. 39, pp. 7165-7173, 2011.

[14] “World Energy Outlook," International Egency Agency (IEA), Tech. Rep., 2012. [Online]. Available: www.iea.org

[15] J. Lopesa, N. Hatziargyriou, J. Mutale, P. Djapic, and N. Jenkins, "Integrating distributed generation into electric power systems: A review of drivers, challenges and opportunities," Electric Power System Res., vol. 77, no. 9, pp. 1189-1203, 2007.

[16] The Danish Government's “Our future Energy”, November 2011.

[17] Danish Energy Authority, Energy Statistics 2013, http://www.ens.dk/sites/ens.dk/files/info/tal-kort/statistiknoegletal/aarlig-energistatistik/energystatistics2013.pdf

[18] Store Project, "Energy needs in Denmark. Executive summary: "Overview of the Danish Power system and RES integration", www.store-project.eu

[19] PV-Tech, “Denmark to reach 2020 installation goal by Q4 2012”, http://www.pvtech.org/news/denmark to reach 2020 installation goal by q4 2012

[20] Energinet.dk, "Solar Power", http://www.energinet.dk/EN/KLIMA-OG-MILJOE/Miljoerapportering/VEproduktion/Sider/Sol.aspx

[21] 2015 European Statistics, Wind in Power (EWEA), February 2016 Available On-line https://windeurope.org/wpcontent/uploads/files/about-wind/statistics/EWEA-Annual-Statistics-2015.pdf

[22] T. Ackermann, N. Martensen, T. Brown, P. Schierhorn, F. Boshell, F. Gafaro, and M. Ayuso, "Scaling up variable renewable power: The role of grid codes," IRENA, Tech. Rep., 2016. [Online]. Available: www.irena.org/publications

[23] “Global Market Outlook for Photovoltaics Until 2016," European Photovoltaic Industry Association, Tech. Rep., 2012. [Online]. Available: www.epia.org

[24] "The global wind report annual market update 2014," Global Wind Energy Council, Tech. Rep., 2014. [Online]. Available: www.gwec.net

[25] "Wind in power 2012 European statistics." The European Wind Energy Association EWEA, Tech. Rep., February 2012. [Online]. Available: www.ewea.org

[26] P. Sørensen, A.D. Hansen, N.A. Cutululis, Ancillary services from wind power plants, 10th Conference on Sustainable Development of Energy, Water and Environment Systems, 27 September - 2 October 2015, Dubrovnik, Croatia.

[27] F.v Hulle et al., Grid support services by wind and solar PV: a review of system needs, technology options, economic benefits and suitable market mechanisms. Synthesis report of the REserviceS project, REserviceS project, 2014. Availa http://www.reservices-project.eu/wp-content/uploads/140724 REserviceS D7.1 Synthesis-report1.pdf

[28] R. Passey, T. Spooner, I. MacGill, M. Watt, and K. Syngellakis, "The potential impacts of grid-connected distributed generation and how to address them: A review of technical and non-technical factors," Energy Policy, vol. 39, no. 10, pp. 6280-6290, 2011.

[29] A. J. Lamadrid and T. Mount, "Ancillary services in systems with high penetrations of renewable energy sources, the case of ramping," Energy Economics, vol. 34, no. 6, pp. 1959 - 1971, 2012.

[30] E.ON Netz GmbH, “Netzanschlussregeln- allgemein. Technische und organisatorische Regeln für den Netzanschluss innerhalb der Regelzone der E.ON Netz GmbH im Bereich der ehemaligen PreussenElektra Netz GmbH \& Co. KG", Rev: December 1st, 2001, Bayreuth, 2001. 
[31] C. Clastres, T. H. Pham, F. Wurtz, and S. Bacha, "Ancillary services and optimal household energy management with photovoltaic production," Energy, vol. 35, no. 1, pp. 55 - 64, 2010 . [Online]. Available: http://www.sciencedirect.com/science/article/pii/S0360544209003673

[32] D. Nock, V. Krishnan, and J. D. McCalley, “Dispatching intermittent wind resources for ancillary services via wind control and its impact on power system economics," Renewable Energy, vol. 71, no. 0, pp. 396 - 400, 2014. [Online]. Available: http://www.sciencedirect.com/science/article/pii/S0960148114003334

[33] N. Sangroniz, J. A. Mora, and M. D. Teixeira, “Review of international grid codes for wind generation," 2009.

[34] "Global Market Outlook for Photovoltaic 2013-2017. EPIA," European Photovoltaic Industry Association EPIA, Tech. Rep., 2013. [Online]. Available: www.epia.org

[35] A. Marinopoulos, F. Papandrea, M. Reza, S. Norrga, F. Spertino, and R. Napoli, "Grid integration aspects of large solar pv installations: Lvrt capability and reactive power/voltage support requirements," in PowerTech, 2011 IEEE Trondheim. IEEE, 2011, pp. 1-8.

[36] Union for the Co-ordination of Transmission of Electricity (UCTE), “P1 - Policy 1: Load-Frequency Control and Performance [C]," 2009.

[37] ENTSO-E, NC RfG: Network Code Requirements for Grid Connection (adopted by Member States in Comitology in June 2015) https://www.entsoe.eu/Documents/Network\%20codes\%20documents/NC\%20RfG/draft ec networkCodesJune.pdf

[38] Energinet.dk Ancillary $\quad$ Services $\quad$ Strategy, Avaliable On-line https://www.energinet.dk/SiteCollectionDocuments/Engelske\%20dokumenter/El/7756611\%20v1\%20Energinet\%20dk's\%20ancillary\%20services\%20strategy.pdf

[39] "Demonstration of Active Power Controls by Utility-Scale PV Power Plant in an Island Grid (Puerto Rico)," by Vahan Gevorgian et al, to be presented at the Wind and Solar Integration Workshop, Nov. 2016

[40] J. Merino, P. Mendoz-Araya, C. Veganzones, "State of the Art and Future Trends in Grid Codes Applicable to Isolated Electrical Systems", Energies, vol. 7, 7936-7954, 2014.

[41] S. Martín-Martínez, E. Gómez-Lázaro, A. Vigueras-Rodríguez, J. A. Fuentes, and A. Molina-García, “Analysis of positive ramp limitation control strategies for reducing wind power fluctuations," IET Renewable Power Generation, vol. 7, no. 6, 593602, November 2013

[42] Available On-line http://www.reservices-project.eu/wp-content/uploads/REserviceS D7.1 Synthesis-Report final.pdf

[43] E.ON Netz GmbH, "Grid Code High and Extra high voltage", Rev. April 1 ${ }^{\text {st }}$ 2006, online: http://www.eon-netz.com/, Bayreuth, 2006.

[44] R. Teodorescu, M. Liserre et al., Grid converters for photovoltaic and wind power systems. John Wiley \& Sons, 2011, vol. 29.

[45] E. Camm, M. Behnke, O. Bolado, M. Bollen, M. Bradt, C. Brooks, W. Dilling, M. Edds, W. Hejdak, D. Houseman et al., "Reactive power compensation for wind power plants," in 2009 IEEE Power \& Energy Society General Meeting. IEEE, 2009, pp. 1-7

[46] J. Kiviluoma, H. Holttinen, Y. H. Wan, R. Scharff, L. Söder, A. Estanqueiro, E. Lannoye, I. Danti-Lopez, E. GómezLázaro, N. Menemenlis, N. Cutululis, D. E. Weir, Q. Zhang, J. Bai, and M. Milligan, "Variability in large scale wind power generation," Wind Energy, vol. 19, no. 9, pp. 1649-1665, September 2016.

[47] M. P. Palsson, T. Toftevaag, K. Uhlen, and J. O. G. Tande, "Large-scale wind power integration and voltage stability limits in regional networks," in Power Engineering Society Summer Meeting, 2002 IEEE, vol. 2.pp. 762-769. 
[48] A. Ellis, R. Nelson, E. Von Engeln, R. Walling, J. MacDowell, L. Casey, E. Seymour, W. Peter, C. Barker, B. Kirby et al., "Reactive power performance requirements for wind and solar plants," in 2012 IEEE Power and Energy Society General Meeting.IEEE, 2012, pp. 1-8.

[49] M. Tsili and S. Papathanassiou, "A review of grid code technical requirements for wind farms," IET Renewable Power Generation, vol. 3, no. 3, pp. 308-332, Sept 2009.

[50] B. I. Craciun, T. Kerekes, D. Séra, and R. Teodorescu, “Overview of recent grid codes for pv power integration,” pp. `959965, May 2012.

[51] Fortmann, J., Pfeiffer, R., Haesen, E., van Hulle, F., Martin, F., Urdal, H., \& Wachtel, S. (2015). Fault-ride-through requirements for wind power plants in the ENTSO-E network code on requirements for generators. IET Renewable power generation, 9(1), 18-24.

[52] H. Geng, C. Liu, and G. Yang, "Lvrt capability of dfig-based wecs under asymmetrical grid fault condition," IEEE Transactions on Industrial Electronics, vol. 60, no. 6, pp. 2495-2509, June 2013.

[53] "Network code requirements for grid connection applicable to all generators," Available at https://www.entsoe.eu/fileadmin/user upload/library/resources/RfG/131016 - NC RfG implementation quideline.pdf, European Network of Transmission System Operators for Electricity, ENTSO-E, Tech. Rep., October 2013.

[54] T. Garcia-Sanchez, E. Gomez-Lazaro, E. Muljadi, M. Kessler, and A. Molina-Garcia, "Statistical and clustering analysis for disturbances: a case study of voltage dips in wind farms," IEEE Transactions on Power Delivery, vol. PP, no. 99, pp. 1-1, 2016.

[55] F. Jiménez, E. Gómez-Lázaro, J. A. Fuentes, A. Molina-García, and A. Vigueras-Rodríguez, "Validation of a double fed induction generator wind turbine model and wind farm verification following the Spanish grid code," Wind Energy, vol. 15, no. 4, pp. 645-659, 2012.

[56] W. Christiansen and D. T. Johnsen, "Analysis of requirements in selected grid codes," Section of Electric power Engineering - Technical University of Denmark (DTU)., Tech. Rep., January 2006.

[57] H. V. Pico and D. Aliprantis, "Voltage ride-through capability verification of wind turbines with fully-rated converters using reachability analysis," IEEE Trans. on Energy Conversion, vol. 29, no. 2, pp. 392-405, June 2014.

[58] H. Villegas Pico and D. Aliprantis, "Voltage ride-through capability verification of wind turbines with fully-rated converters using reachability analysis," IEEE Trans. on Energy Conversion, vol. 29, no. 2, pp. 392-405, June 2014.

[59] IEC 61400-21 ed. 2, Wind turbine generator systems - Part 21: Measurement and assessment of power quality characteristics of grid connected wind turbines (2008).

[60] IEC 61400-27-1:2015 Electrical simulation models - Wind turbines (2015)

[61] S. Eftekharnejad, V. Vittal, G. Heydt, B. Keel, and J. Loehr, "Small signal stability assessment of power systems with increased penetration of photovoltaic generation: A case study," IEEE Transactions on Sustainable Energy, vol. 4, no. 4, 960-967, Oct 2013.

[62] "Assessment of the system security with respect to disconnection rules of photovoltaic panels," Available at https://www.entsoe.eu/publications/system-operationsreports/Documents/120530_Assessment_of_the_System_security_with_respect_to_disconnection_rules_of_PV_Panels. pdf, European Network of Transmission System Operators for Electricity, ENTSO-E, Tech. Rep., April 2012.

[63] REE, P.O. 12.3 Requisitos de respuesta frente a huecos de tensión de las instalaciones eólicas (in Spanish), Red Eléctrica de España, October 2006. 
[64] "Royal Decree 1565/2010, by which regulates and modifies certain aspects of the activity of production of electric energy in special regime. (In Spanish)," Tech. Rep., November 2010.

[65] BDEW, Generating Plants to Connected the MediumVoltage Network. [Online]. Available: http://www.bdew.de/internet.nsf/id/A2A0475F2FAE8F44C12578300047C92F/\$̧file/BDEW RL EA-am-MS-Netz engl.pdf

[66] D. Montoro, "Recommendations for unified technical regulations for grid-connected pv systems," available

http://www.pvsunrise.eu/fileadmin/PVS docs/images/Recommendations for unified technical regulations for gridconnected PV systems Public .pdf , SUNRISE project - European Photovoltaic Industry Association, the European Construction Industry Federation, the European Association of Electrical Contractors, International Union of Architects, Tech. Rep., 2009.

[67] B. Craciun, T. Kerekes, D. Sera, and R. Teodorescu, "Overview of recent grid codes for pv power integration," in Optimization of Electrical and Electronic Equipment (OPTIM), 2012 13th International Conference on, May 2012, pp. 959-965.

[68] L. Zhan and M. H. Bollen, "Characteristic of voltage dips (sags) in power systems," IEEE Trans. on Power Delivery, vol. 15, no. 2, pp. 827-832, 2000.

[69] M. H. Bollen and L. Zhang, "Different methods for classification of three-phase unbalanced voltage dips due to faults," Electric power systems research, vol. 66, no. 1, pp. 59-69, 2003.

[70] E. Gómez-Lázaro, J. A. Fuentes, A. Molina-García, and M. Cañas-Carretón, “Characterization and visualization of voltage dips in wind power installations," IEEE Trans. on Power Delivery, vol. 24, no. 4, pp. 2071-2078, 2009.

[71] M. Muhamad, N. Mariun, and M. A. M. Radzi, "The effects of power quality to the industries," 5th Student Conference on Research and Development, 2007.

[72] E. Muljadi, Z. Mills, R. Foster, J. Conto, and A. Ellis, "Fault analysis at a wind power plant for one year of observation," in Power and Energy Society General Meeting - Conversion and Delivery of Electrical Energy in the 21st Century, 2008 IEEE, July 2008, pp. 1-7.

[73] M. Bollen, M. Stephens, S. Djokic, K. Stockman, B. Brumsickle, J. Milanovic, J. Romero Gordón, R. Neumann, G. Ethier, F. Córcoles, A. Ferguson, P. Goossens, P. Ligot, A. Lopes Leiria, P. Marteyn, A. McEachern, J. Mentzer, I. McMichael, U. Minnaar, K. Reusel, and F. Zavoda, “Voltage dip immunity of equipment and installations," CIGRE, Tech. Rep., 2010.

[74] S. Elphick, V. Smith, V. Gosbell, and R. Barr, "The australian long term power quality survey project update," 14 International Conference on Harmonics and Quality of Power, pp. 1-7, 2010.

[75] A. Honrubia-Escribano, E. Gómez-Lázaro, A. Molina-García, and J. Fuentes, "Influence of voltage dips on industrial equipment: Analysis and assessment," International Journal of Electrical Power \& Energy Systems, vol. 41, no. 1, pp. 87-95, 2012.

[76] D. Flynn, Z. Rather, A. Ardal, S. D’Arco, A. D. Hansen, N. A. Cutululis, P. Sorensen, A. Estanquiero, E. Gómez-Lázaro, N. Menemenlis, C. Smith, and Y. Wang, "Technical impacts of high penetration levels of wind power on power system stability," Wiley Interdisciplinary Reviews: Energy and Environment, 2016.

[77] E. Gomez-Lazaro, M. C. Bueso, M. Kessler, S. Martin-Martinez, J. Zhang, B. M. Hodge, and A. Molina-Garcia, "Probability density function characterization for aggregated large-scale wind power based on Weibull mixtures," Energies, vol. 9(2), no. 91, pp. 1-15, February 2016.

[78] L. Bird, D. Lew, M. Milligan, E. M. Carlini, A. Estanqueiro, D. Flynn, E. Gomez-Lazaro, H. Holttinen, N. Menemenlis, A. Orths, P. Børre-Eriksen, J. C. Smith, L. Soder, P. Sorensen, A. Altiparmakis, Y. Yasuda, and J. Miller, "Wind and solar energy 
curtailment: A review of international experience," Renewable \& Sustainable Energy Reviews, vol. 65, pp. 577-586, November 2016.

[79] D. Lew, L. Bird, E. Carlini, A. Estanqueiro, D. Flynn, E. Gómez-Lázaro, B. Lange, N. Menemenlis, A. Orths, I. Pineda, C. Smith, L. Soder, P. Sørensen, Y. Yasuda, and H. Holttinen, "Wind and solar curtailment: International experience and practices," in International Workshop on Large-Scale Integration of Wind Power into Power Systems as well as on Transmission Networks for Offshore Wind Farms. London, United Kingdom: Energynautics GmbH, October 2013, pp. 1-7.

[80] S. Martín-Martínez and E. Gómez-Lázaro, "Analysis of hydropower flexibility during wind energy curtailments: the Spanish case," in IEEE PES General Meeting.Denver, CO, USA: IEEE Power \& Energy Society, July 2015.

[81] L. Bird, J. Cochran, and X. Wang, "Wind and solar energy curtailment: experience and practices in the united states," NREL, March, 2014.

[82] H. Holttinen, P. Meibom, A. Orths, B. Lange, M. O’Malley, J. O. Tande, A. Estanqueiro, E. Gómez-Lázaro, L. Söder, G. Strbac, J. C. Smith, and F. V. Hulle, "Impacts of large amounts of wind power on design and operation of power systems, results of IEA collaboration," Wind Energy, vol. 14, no. 2, pp. 179-192, March 2011.

[83] S. Martín-Martínez, E. Gómez-Lázaro, A. Honrubia-Escribano, M. Cañas, and A. Molina-García, "Wind power curtailment analysis under generation flexibility requirements: the Spanish case study," in IEEE PES General Meeting. Denver, CO, USA: IEEE Power \& Energy Society, July 2015, pp. 1-5.

[84] D. J. Burke and M. J. O’Malley, “Factors influencing wind energy curtailment," IEEE Transactions on Sustainable Energy, vol. 2, no. 2, pp. 185-193, 2011.

[85] S. Fink, C. Mudd, K. Porter, and B. Morgenstern, "Wind energy curtailment case studies," NREL subcontract report, NREL/SR550, vol. 46716, 2009.

[86] Y. Yasuda, L. Bird, E. M. Carlini, A. Estanqueiro, D. Flynn, A. Forcione, E. Gómez-Lázaro, P. Higgins, H. Holttinen, D. Lew, S. Martín-Martínez, J. McCam, N. Menemenlis, and J. C. Smith, "International comparison of wind and solar curtailment ratio," in International Workshop on Large-Scale Integration of Wind Power into Power Systems as well as on Transmission Networks for Offshore Wind Farms. Brussels, Belgium: Energynautics GmbH, October 2015, pp. 1-6.

[87] R. Piwko, D. Osborn, R. Gramlich, G. Jordan, D. Hawkins, and K. Porter, "Wind energy delivery issues [transmission planning and competitive electricity market operation]," IEEE power and energy magazine, vol. 3, no. 6, pp. 47-56, 2005.

[88] J. C. Smith, D. Osborn, R. Zavadil, W. Lasher, E. Gómez-Lázaro, T. Trötscher, J. O. Tande, M. Korpås, F. V. Hulle, A. Estanqueiro, L. Dale, and H. Holttinen, "Transmission planning for wind power, status and prospects," in International Workshop on Large-Scale Integration of Wind Power into Power Systems as well as on Transmission Networks for Offshore Wind Farms. Quebec, Canada: Energynautics GmbH, October 2010, pp. 371-382.

[89] J. C. Smith, D. Osborn, R. Zavadil, W. Lasher, E. Gómez-Lázaro, A. Estanqueiro, T. Trötscher, J. Tande, M. Korpås, F. V. Hulle, H. Holttinen, A. Orths, D. Burke, M. O'Malley, J. Dobschinski, B. Rawn, M. Gibescu, and L. Dale, "Transmission planning for wind energy: Status and prospects," Wiley Interdisciplinary Reviews: Energy and Environment, vol. 2, no. 1, 1-13, January 2013.

[90] J. Zhang, B.-M. Hodge, J. Miettinen, H. Holttinen, E. Gómez-Lázaro, J. Dobschinski, R. Verzijbergh, and N. Cutululis, “Analysis of variability and uncertainty in wind power forecasting: An international comparison," in International Workshop on LargeScale Integration of Wind Power into Power Systems as well as on Transmission Networks for Offshore Wind Farms. London, United Kingdom: Energynautics GmbH, October 2013, pp. 1-6.

[91] P.O. 3.7 Programación de la generación de origen renovable no gestionable (in Spanish), Red Eléctrica de España, May 2009. 
[92] L. Kane and G. Ault, "A review and analysis of renewable energy curtailment schemes and principles of access: Transitioning towards business as usual," Energy Policy, vol. 72, pp. 67-77, 2014.

[93] EirGrid and SONL. All island TSO facilitation of renewables studies, Dublin, Ireland; 2010

[94] S. Martin-Martínez, A. Vigueras-Rodríguez, E. Gómez-Lázaro, A. Molina-García, E. Muljadi, and M. Milligan, Advances in wind power. Rijeka, Croatia: Intech, November 2012, ch. Wind Power Variability and Singular Events, p. 373.

[95] S. Martín-Martínez, E. Gómez-Lázaro, A. Molina-García, and A. Honrubia-Escribano, "Impact of wind power curtailments on the Spanish power system operation," in IEEE PES General Meeting. National Harbor, MD, USA: IEEE Power \& Energy Society, July 2014, pp. 1-5.

[96] Y. Yasuda, A. R. Årdal, E. M. Carlini, A. Estanqueiro, D. Flynn, E. Gómez-Lázaro, D. H. Hernand, H. Holttinen, F. V. Hulle, J. Kiviluoma, J. Kondoh, B. Lange, N. Menemenlis, M. Milligan, A. Orths, C. Smith, and L. Söder, "Flexibility chart. evaluation on diversity of flexibility in various areas," in International Workshop on Large-Scale Integration of Wind Power into Power Systems as well as on Transmission Networks for Offshore Wind Farms. London, United Kingdom: Energynautics GmbH, October 2013.

[97] D. Huertas, H. Farahmand, H. Holttinen, J. Kiviluoma, E. Rinne, L. Söder, M. Milligan, E. Ibañez, E. Gomez-Lazaro, S. MartínMartínez, A. Estanqueiro, L. Rodrigues, L. Carr, S. van Roon, A. Orths, P. B. Eriksen, A. Forcione, and N. Menemenlis, "Hydro power flexibility for power systems with variable renewable energy sources (RES). An IEA Task 25 collaboration," Wiley Interdisciplinary Reviews: Energy and Environment, 2016.

[98] A. Orths, H. Abildgaard, F. van Hulle, J. Kiviluoma, B. Lange, M. O’Malley, D. Flynn, A. Keane, J. Dillon, E. M. Carlini, J. O. Tande, A. Estanqueiro, E. Gómez-Lázaro, L. Söder, M. Milligan, J. C. Smith, and C. Clark, Expert group report on recommended practices. 16 wind integration studies, H. Holttinen, Ed. Helsinki, Finland: International Energy Agency Implementing Agreement for Co-operation in the Research, Development, and Deployment of Wind Energy Systems, September 2013.

[99] J. C. Smith, A. Estanqueiro, E. Gómez-Lázaro, F. van Hulle, T. Trötcher, L. Dale, and H. Holttinen, “Transmission planning for wind energy. Status and prospects," in European Wind Energy Conference and Exhibition-IEAWIND Side Event. Brussels, Belgium: European Wind Energy Association (EWEA), March 2011.

[100] H. Holttinen, M. Milligan, E. Ela, N. Menemenlis, J. Dobschinski, B. Rawn, R. J. Bessa, D. Flynn, E. GómezLázaro, and N. Detlefsen, "Methodologies to determine operating reserves due to increased wind power," IEEE Transactions on Sustainable Energy, vol. 3, no. 4, pp. 713-723, October 2012.

[101] J. Cochran, M. Miller, M. Milligan, E. Ela, D. Arent, A. Bloom, M. Futch, J. Kiviluoma, H. Holtinnen, A. Orths, E. GómezLázaro, S. Martín-Martínez, S. Kukoda, G. Garcia, K. M. Mikkelsen, Z. Yongqiang, and K. Sandholt, “Market evolution: Wholesale electricity market design for 21 st century power systems," National Renewable Energy Laboratory, IBM, VTT Technical Research Centre of Finland, Energinet.dk, Universidad de Castilla La Mancha, International Copper Association, Global Green Growth Institute, China National Renewable Energy Center, pp. 1-57, October 2013. 